The British Institution of Radio Engineers : Premiums for 1954

THe British Institution of Radio Engineers has awarded the following premiums for papers on the subjects indicated, published in the Journal of the Institution during 1954: Clerk Maxwell Premium (the premier award of the Institution), to F. N. H. Robinson (Clarendon Laboratory, Oxford), mierowave shot noise in electron beams and the minimum noise factor of travelling-wave tubes and klystrons; Heinrich Hertz Premium, to Dr. T. B. Tomlinson (formerly of the University of Southampton), partition components of flicker noise ; Louis Sterling Premium, to L. H. Bedford (Marconi's Wireless Telegraph Co., Ltd.), problems of television cameras and camera tubes; Sir J. C. Bose Premium, to S. Deb (Institute of Radio Physics and Electronics, University of Calcutta), the decay of emission from an oxide-coated cathode due to adsorption of matter liberated from the anode; Brabazon Premium, to J. W. Jenkins, J. H. Evans, G. A. G. Wallace and D. Chambers (A. C. Cossor, Ltd.), a high-definition general-purpose radar; Marconi Premium, to W. T. Brown (British Telecommunications Research, Ltd.), some factors in the engineering design of very-high-frequency multichannel telephone equipment; Leslie McMichael Premium, to Dr. G. N. Patchett (Bradford Technical College), a critical review of synchronizing separators, with particular reference to correct interlacing; Students' Premium, to R. W. Walker (King's College, Newcastle upon Tyne), an electronic random selector. Premiums have also been awarded to the following authors of papers read at the Industrial Electronics Convention, held at Oxford in July 1954 : P. Huggins (Sargrove Electronics, Ltd.), statistical computers as applied to industrial control ; C. W. Miller (Metropolitan-Vickers Electrical Co., Ltd.), industrial radiography and the linear accelerator; K. Kandiah and D. W. Chambers (Atomic Energy Research Establishment), multi-electrode counting tubes; J. L. Thompson (J. Langham Thompson, Ltd.), wire strain-gauge transducers for the measurement of pressure, force, displacement and acceleration; and M. T. Elvy (Redifon, Ltd.), electronic heating and the woodworking industry.

\section{The Rubber-Stichting}

THe Rubber-Stichting (Rubber Foundation), established in 1936 with headquarters in Delft, is one of several research organizations operating in Europe and in the Far East in the interests of natural rubber. Financed by means of a cess levied on rubber produced in Indonesia, the recently announced intention of the Indonesian Government to remove the Foundation to Bogor has come as a severe shock to those interested in research on rubber. The staff, numbering more than two hundred, show little inclination to emigrate, and the possibility of the work in progress being stopped must be faced. The RubberStichting has been engaged in fundamental research for long enough for its work to have won world-wide recognition. It is impossible here even to mention all of it; but of particular significance is its work in the field of latex, which, as a result, can now be used for the direct preparation of chlorinated rubber, rubber hydrochloride, cyclized rubber, and even ebonite. The preparation of reinforced rubber by the formation in the latex of synthetic resin complexes has been of particular interest from both the theoretical and practical points of view. In the labora- tories at Delft pilot-plant research has been carried out on flame-resistant latex foam and rubber hydrochloride monofilaments ; asphalt-rubber compositions for roads have been developed, a fleet of cars has been used for road-testing experimental tyre compositions, and cement-latex compositions for flooring have been studied. Fundamental investigations have been undertaken relating to vulcanization, abrasion, and the permeability of rubber. It is interesting to recall that out of the fifty papers accepted for presentation at last year's International Rubber Technology Conference, four emanated from the Rubber-Stichting.

A great deal of success has been achieved in publicizing the advantages and possibilities of rubber among technical men in other industries, in the education of rubber technologists, and in the holding of international symposia and conferences on different aspects of rubber technology. An efficient documentation centre for rubber is maintained, especially noteworthy for its work on correlation of rubber patents. In this field it has worked in close co-operation with the Intelligence Division of the Research Association of British Rubber Manufacturers, in which connexion mention must be made of its share in preparing and maintaining the International System for Classification of Rubber Information, the secretariat of which is at Delft.

\section{Education in East Africa}

Four years ago the Nuffield Foundation showed its interest in African education by sponsoring, jointly with the Colonial Office, the Jeffery and Binns Missions. It has now given further assistance to the education of Africans by making a grant of $£ 50,000$ towards the work of the Institute of Education at Makerere College, Uganda. A fifth of this sum will provide research accommodation and other facilities for the work of the Institute, while the balance forms an endowment fund enabling a Nuffield Research Fellow to pursue some line of educational study important to East Africa. In choosing the subject of the first research project, it was borne in mind that the Binns Mission had directed attention to the need for better courses in vernacular languages and English in the primary schools of East Africa, and advocated a much earlier start in the teaching of English than hitherto. But little is known about the best methods of teaching English to the children of East Africa, and an imperfect knowledge of the language holds up their education in all subjects well into the secondary school. After consultation with the Directors of Education of East Africa, and with their unanimous support, it has been agreed to devote the first few years of the Nuffield grant to an attack on problems of teaching English and the teaching of other school subjects in English.

\section{Research on the Tropical Swamps of East and Central Africa}

THE Nuffield Foundation has given $£ 21,900$ for a four-year scheme of research on the biology of tropical swamps, to be directed by Prof. L. C. Beadle, professor of biology in Makerere College, Uganda. The area covered by swamps in East and Central Africa is enormous. In them are accurnulating a large proportion of the plant nutrients washed in from the surrounding land which are being preserved under anaerobic conditions. Exploitation by drainage and dry cultivation has begun; but this is not the 